\title{
Association of alpha-1-antitrypsin deficiency with vitamin D status: who is most at risk of getting severe COVID-19?
}

\author{
Ghazaleh Shimi ${ }^{1} \cdot$ Hamid Zand $^{1}$ (D)
}

Received: 25 January 2021 / Revised: 11 March 2021 / Accepted: 14 March 2021 / Published online: 19 March 2021

(c) The Author(s), under exclusive licence to Springer Nature Switzerland AG 2021

\begin{abstract}
Introduction Coronavirus disease 2019 (COVID-19), a new disease that we do not know yet how to treat, is rapidly evolving and has forced us to stay indoors. Surprisingly, a broad range of symptoms has been reported since COVID-19 emergence. Individual variations in susceptibility to SARS-CoV-2 can be due to non-genetic and genetic factors. Alpha-1-antitrypsin deficiency (AATD) is an inherited condition that is associated with an increased risk of liver and lung diseases which may increase susceptibility to COVID-19 infection. At the same time, there could be a possibility of developing non-hereditary AATD.

Discussion In addition to some evidence showing the role of vitamin D deficiency in COVID-19 pathology, it has been recognized that there is a biological link between AAT and vitamin D. Therefore, here we offer a new perspective that lower vitamin D levels in COVID-19 patients can cause acquired AATD that provide a condition with more disease severity and a higher risk of death. As a consequence, COVID-19 individuals with vitamin D deficiency may have a higher risk of morbidity and mortality.

Conclusion Therefore, early vitamin D and AAT assessments and optimal interventions could be helpful to prevent severe COVID-19 outcomes.
\end{abstract}

Keywords Coronavirus disease 2019(COVID-19) · Alpha-1-antitrypsin deficiency · Vitamin D

$\begin{array}{ll}\begin{array}{l}\text { Abbreviations } \\ \text { COVID-19 }\end{array} & \begin{array}{l}\text { Coronavirus disease 2019 } \\ \text { SARS-CoV-2 }\end{array} \\ & \begin{array}{l}\text { Severe acute respiratory syndrome coro- } \\ \text { navirus 2 }\end{array} \\ \text { AATD } & \text { Alpha-1-antitrypsin deficiency } \\ \text { AAT } & \text { Alpha-1-antitrypsin } \\ \text { TMPRSS2 } & \text { Transmembrane serine protease 2 } \\ \text { ADAM17 } & \text { A disintegrin and metalloproteinase-17 } \\ \text { ACE2 } & \text { Angiotensin-converting enzyme 2 } \\ \text { RAS } & \text { Renin-angiotensin-aldosterone system } \\ \text { 1,25(OH)2D3 } & \text { 1,25-Dihydroxy-vitamin D3 }\end{array}$

Responsible Editor: John Di Battista.

Hamid Zand

hamid_zand@sbmu.ac.ir; hamidzand@gmail.com

Ghazaleh Shimi

ghazaleh_shimi@yahoo.com

1 Department of Cellular and Molecular Nutrition, Faculty of Nutrition Science and Food Technology, National Nutrition and Food Technology Research Institute, Shahid Beheshti University of Medical Sciences, 1981619573 Tehran, Iran

\author{
IL-10 Interleukin 10 \\ ARDS Acute respiratory distress syndrome \\ 25(OH)VD 25-Hydroxy-vitamin D \\ COPD Chronic obstructive pulmonary disease
}

\section{Introduction}

In December 2019, coronavirus disease 2019 (COVID-19) caused by severe acute respiratory syndrome coronavirus 2 (SARS-CoV-2) appeared in China and led to a rapidly progressing pandemic. Following that, communications were declined and people were quarantined in their homes. Strangely and sadly enough, responses and reactions to COVID-19 appear to be widely different, ranging from asymptomatic or mild to severe conditions and death, among different people and regions. Non-genetic factors, including age, comorbid conditions such as cancer and cardiovascular disorders, and environmental risk factors like air pollution, may confer differential susceptibility to SARS-CoV-2 infection. Similarly, host genetic factors can influence the severity of the disease. Therefore, understanding the non-genetic/ 
genetic effects on host immune function may help identify why some COVID-19 cases display severe disease, while others experience mild to no symptoms? [1-3].

\section{The effect of alpha-1-antitrypsin deficiency on covid-19 infection}

Among genetic factors, one candidate gene might be SERPINA1 which encodes the alpha-1-antitrypsin (AAT) protein. AAT is an acute-phase protein that is mainly produced by liver cells and subsequently secreted into the plasma but is also secreted to a lesser extent by monocytes, macrophages, pulmonary alveolar cells, and intestinal epithelium [4]. In addition to its anti-proteinase function and inhibition of neutrophil proteinases including neutrophil elastase, cathepsin G, and proteinase 3; AAT has several known non-proteinase effects including anti-inflammatory and immunomodulatory characteristics and antimicrobial/ antiviral properties [5, 6]. Hereditary AATD is characterized by decreased serum level or abnormal AAT functions and is also associated with an increased risk of liver and lung diseases [7] which may increase susceptibility to COVID-19 infection. Considering the information provided, the article by Shapira et al. reported that frequencies of AATD alleles were positively correlated with the COVID-19 fatality rate [8]. Moreover, since the Lombardia region in Italy with $37.8 \%$ of COVID-19 casualties, also had $47 \%$ of all AATD cases, Vianello and Braccioni suggested that AATD may explain the high mortality rate of COVID-19 [7]. Notably, these findings could be due to the fact that TMPRSS2 (transmembrane serine protease 2) which promotes COVID-19 cell entry, cannot be suppressed by AAT in AATD patients. Besides, AAT improves inflammatory conditions by reducing ADAM17 (a disintegrin and metalloproteinase-17) activity which is responsible for the breakdown of ACE2 (angiotensin-converting enzyme 2) and the imbalance of the renin-angiotensin-aldosterone system (RAS) [7, 9].

Remarkably, Ray et al. demonstrated that while any underlying genetic reason for the observed AATD had been ruled out in their tropical pulmonary eosinophilia subjects, acquired AATD existed as a result of the chronic inflammation and oxidative stress. Ray et al., also, had ruled out the possibility of any intestinal AAT loss in their worm-infested pulmonary eosinophilia subjects [10]. Accordingly, it could be possible to assume non-hereditary AATD development in COVID-19 patients. Thus, in the following section, this article will dive into a way that how AATD acquisition can be developed by COVID-19 patients?

\section{The link between vitamin D status and alpha-1-antitrypsin levels}

AATD and vitamin D deficiency are tightly linked to inflammation and autoimmunity $[11,12]$. Both AAT and vitamin D have strong immune-modulating roles in the airways environment [13]. A study by Dimeloe et al. reported that vitamin $\mathrm{D}$ active form $(1,25(\mathrm{OH}) 2 \mathrm{D} 3)$ causes CD4 + T cells to secrete AAT, and AAT, via direct interaction with complement C3a, promotes IL-10 (interleukin 10) secretion; meaning that AAT is essential for 1,25(OH)2D3 to induce IL-10. Dimeloe et al., also, stated that $1,25(\mathrm{OH}) 2 \mathrm{D} 3$ failed to enhance IL-10 transcription in $\mathrm{CD} 4+\mathrm{T}$ cells from hereditary AATD individuals (PiZZ) compared to the healthy subjects [13]. This implies that $1,25(\mathrm{OH}) 2 \mathrm{D} 3$ is a key upstream regulator in this antiinflammatory axis in $\mathrm{CD} 4+\mathrm{T}$ cells.

At the same time, Lindley et al.'s study on type 2 diabetic patients showed that low circulating levels of AAT were positively associated with lower $25(\mathrm{OH}) \mathrm{VD}$ levels, suggesting that $25(\mathrm{OH}) \mathrm{VD}$ deficiency may predispose type 2 diabetic patients to AATD which may cause a higher incidence of COPD (chronic obstructive pulmonary disease) in diabetes [14]. Moreover, Crane-Godreau et al.'s study on mice exposed to cigarette smoke reported that vitamin D deficiency causes a significantly lower AAT expression in the lungs and emphysema [15].

In the meantime, vitamin D and COVID-19, both, have the same target which is RAS and the immune system. Luckily, vitamin D regulates the RAS and avoids bradykinin accumulation, and has a strong protective effect against acute lung injury and acute respiratory distress syndrome (ARDS). Conversely, COVID-19 kills through bradykinin storm, along with the cytokine storm. It is a well-known fact that vitamin D decreases remarkably in severely ill patients with COVID-19 [16-18]. Several studies have reported the possible link between vitamin D concentrations and COVID-19 severity and fatality [19-22]. However, not much is known about the potential role of vitamin $\mathrm{D}$ in preventing and treating COVID-19 infection. Yet, here we suggested that vitamin D deficient COVID-19 individuals may acquire AATD, and that is what makes the illness more severe once the patients are infected.

\section{Conclusion}

In conclusion, lower vitamin D levels in COVID-19 patients may cause acquired AATD that provides a condition with more disease severity and a higher risk of death. Further investigations are required to demonstrate 
the association between AAT levels and vitamin D status. Notably, vitamin D and AAT assessments would be essential to detect deficient persons and optimal interventions could be helpful to prevent severe COVID-19 outcomes.

Author contributions Conceptualization: GS, HZ; Writing-original draft preparation: GS; Writing—review and editing: GS, HZ; Supervision: HZ.

Funding No funds, grants, or other support was received.

\section{Declarations}

Conflict of interest The authors have no conflict of interest to declare that are relevant to the content of this article.

\section{References}

1. Carter-Timofte ME, Jørgensen SE, Freytag MR, Thomsen MM, Brinck Andersen N-S, Al-Mousawi A, et al. Deciphering the role of host genetics in susceptibility to severe COVID-19. Front Immunol. 2020. https://doi.org/10.3389/fimmu.2020.01606.

2. Anastassopoulou C, Gkizarioti Z, Patrinos GP, Tsakris A. Human genetic factors associated with susceptibility to SARS-CoV-2 infection and COVID-19 disease severity. Hum Genomics. 2020;14(1):40. https://doi.org/10.1186/s40246-020-00290-4.

3. Hou Y, Zhao J, Martin W, Kallianpur A, Chung MK, Jehi L, et al. New insights into genetic susceptibility of COVID-19: an ACE2 and TMPRSS2 polymorphism analysis. BMC Med. 2020;18(1):216. https://doi.org/10.1186/s12916-020-01673-z.

4. Karatas E, Bouchecareilh M. Alpha 1-antitrypsin deficiency: a disorder of proteostasis-mediated protein folding and trafficking pathways. Int J Mol Sci. 2020. https://doi.org/10.3390/ijms210414 93.

5. Sapey E. Neutrophil modulation in alpha-1 antitrypsin deficiency. Chronic Obstructive Pulmonary Dis (Miami, Fla). 2020;7(3):24759. https://doi.org/10.15326/jcopdf.7.3.2019.0164.

6. Mohammad H, Pawan S, Mehdi E, Mohammad N, Abdolkarim M-R, Hamid M, et al. Alpha-1 antitrypsin: it's role in health and disease. AntiInflammatory Antiallergy Agents Med Chem. 2010;9(4):279-88. https://doi.org/10.2174/187152301100904 0279.

7. Vianello A, Braccioni F. Geographical overlap between alpha-1 antitrypsin deficiency and COVID-19 infection in Italy: Casual or causal? Arch Bronconeumol. 2020;56(9):609-10. https://doi.org/ 10.1016/j.arbres.2020.05.015.

8. Shapira G, Shomron N, Gurwitz D. Ethnic differences in alpha-1 antitrypsin deficiency allele frequencies may partially explain national differences in COVID-19 fatality rates. FASEB J. 2020;34(11):14160-5. https://doi.org/10.1096/fj.202002097.

9. de Loyola MB, Dos Reis TTA, de Oliveira G, da Fonseca Palmeira J, Argañaraz GA, Argañaraz ER. Alpha-1-antitrypsin: a possible host protective factor against Covid-19. Rev Med Virol. 2020. https://doi.org/10.1002/rmv.2157.
10. Ray D, Harikrishna S, Immanuel C, Victor L, Subramanyam S, Kumaraswami V. Acquired alpha 1-antitrypsin deficiency in tropical pulmonary eosinophilia. Indian J Med Res. 2011;134(1):79-82.

11. Dankers W, Colin EM, van Hamburg JP, Lubberts E. Vitamin D in autoimmunity: molecular mechanisms and therapeutic potential. Front Immunol. 2016;7:697. https://doi.org/10.3389/fimmu.2016. 00697.

12. de Serres F, Blanco I. Role of alpha- 1 antitrypsin in human health and disease. J Intern Med. 2014;276(4):311-35. https://doi.org/ 10.1111/joim.12239.

13. Dimeloe S, Rice LV, Chen H, Cheadle C, Raynes J, Pfeffer P, et al. Vitamin D $(1,25(\mathrm{OH}) 2 \mathrm{D} 3)$ induces $\alpha-1$-antitrypsin synthesis by $\mathrm{CD} 4+\mathrm{T}$ cells, which is required for 1,25(OH) 2D3-driven IL-10. J Steroid Biochem Mol Biol. 2019;189:1-9. https://doi.org/10. 1016/j.jsbmb.2019.01.014.

14. Lindley VM, Bhusal K, Huning L, Levine SN, Jain SK. Reduced $25(\mathrm{OH})$ Vitamin D association with lower alpha-1-antitrypsin blood levels in type 2 diabetic patients. J Am College Nutr. 2020. https://doi.org/10.1080/07315724.2020.1740629.

15. Crane-Godreau MA, Black CC, Giustini AJ, Dechen T, Ryu J, Jukosky JA, et al. Modeling the influence of vitamin D deficiency on cigarette smoke-induced emphysema. Front Physiol. 2013;4:132. https://doi.org/10.3389/fphys.2013.00132.

16. Weir EK, Thenappan T, Bhargava M, Chen Y. Does vitamin D deficiency increase the severity of COVID-19? Clin Med (Lond). 2020;20(4):e107-8. https://doi.org/10.7861/clinmed.2020-0301.

17. Malek Mahdavi A. A brief review of interplay between vitamin $D$ and angiotensin-converting enzyme 2: implications for a potential treatment for COVID-19. Rev Med Virol. 2020;30(5):e2119-e. https://doi.org/10.1002/rmv.2119.

18. Jain A, Chaurasia R, Sengar NS, Singh M, Mahor S, Narain S. Analysis of vitamin D level among asymptomatic and critically ill COVID-19 patients and its correlation with inflammatory markers. Sci Rep. 2020;10(1):20191. https://doi.org/10.1038/ s41598-020-77093-z.

19. Katz J, Yue S, Xue W. Increased risk for COVID-19 in patients with vitamin D deficiency. Nutrition. 2021;84:111106. https://doi. org/10.1016/j.nut.2020.111106.

20. Ali N. Role of vitamin D in preventing of COVID-19 infection, progression and severity. J Infect Public Health. 2020;13(10):1373-80. https://doi.org/10.1016/j.jiph.2020.06.021.

21. Ricci A, Pagliuca A, D’Ascanio M, Innammorato M, De Vitis C, Mancini R, et al. Circulating Vitamin D levels status and clinical prognostic indices in COVID-19 patients. Respir Res. 2021;22(1):76. https://doi.org/10.1186/s12931-021-01666-3.

22. Kazemi A, Mohammadi V, Aghababaee SK, Golzarand M, Clark CCT, Babajafari S. Association of Vitamin D status with SARSCoV-2 infection or COVID-19 severity: a systematic review and meta-analysis. Adv Nutr. 2021. https://doi.org/10.1093/advances/ nmab012.

Publisher's Note Springer Nature remains neutral with regard to jurisdictional claims in published maps and institutional affiliations. 